\title{
SOROPREVALÊNCIA DE HIV 1/2 EM DOADORES DE SANGUE PROVENIENTES DO HEMOCENTRO DE CERES-GO, ENTRE JANEIRO DE 2010 A DEZEMBRO DE 2013.
}

SEROPREVALENCE OF HIV 1/2 IN BLOOD DONORS FROM HEMOCENTRO

DE CERES-GO FROM JANUARY OF 2010 TO DECEMBER OF 2013.

${ }^{1,2}$ Milce Costa; ${ }^{3}$ Valéria Menezes de Souza; ${ }^{4}$ Doraci Maria dos Santos Trindade;

${ }^{5}$ Anapaula Gonçalves de Souza Portes; ${ }^{5}$ Raiane Antunes Sampaio

\section{RESUMO}

Introdução: A Síndrome da Imunodeficiência Adquirida (SIDA) é uma doença infecciosa provocada pelo Vírus da Imunodeficiência Humana (VIH). A disseminação do HIV ocorre através da relação sexual sem proteção, contato com sangue contaminado e transmissão vertical durante o parto ou pelo aleitamento materno. Atualmente, existem poucos dados na literatura científica em relação à prevalência de doenças transmissíveis por transfusões sanguíneas na população brasileira. Dessa forma, o presente estudo teve por objetivo analisar a soroprevalência de HIV 1/2 entre os candidatos a doadores de sangue da região do Vale de São Patrício e Serra da Mesa, atendidos no Hemocentro Regional de Ceres-GO (Hemoceres). Metodologia: Trata-se de um estudo retrospectivo de levantamento de dados, de aspecto qualiquantitativo. Os dados foram coletados no Hemoceres, no período compreendido entre janeiro de 2010 a dezembro de 2013. Resultados e discussão: Do total de 8.838 doações realizadas no Hemoceres, apenas 07 indivíduos $(0,08 \%)$ apresentaram sorologia positiva para HIV 1/2. Acredita-se que as baixas prevalências de doadores inaptos detectadas no Hemoceres possam ser explicadas a princípio, pela eficácia da triagem clínica realizada com o candidato na doação. Verificou-se uma maior prevalência de inaptidão sorológica para HIV1/2 em indivíduos do gênero masculino. Quanto ao estado civil dos doadores inaptos com sorologia positiva para HIV, verificou-se que $57,1 \%$ eram casados e $42,9 \%$ solteiros. Em relação à faixa etária, 57,1\% dos indivíduos tinham acima de 29 anos. Conclusão: Diante dos dados obtidos

\footnotetext{
${ }^{1}$ Doutora em Medicina Tropical. Docente na FACER - Faculdade de Ceres, Ceres - GO, Brasil.

${ }^{2}$ Autora correspondente: milcebiomol@yahoo.com.br

${ }^{3}$ Acadêmica do Curso de Farmácia. FACER - Faculdade de Ceres, Ceres - GO, Brasil.

${ }^{4}$ Odontóloga. Especialista em Ortopedia Facial e Ortodontia e Saúde Pública. Docente na FACER - Faculdade de Ceres, Ceres - GO, Brasil.

${ }^{5}$ Enfermeira. Faculdade de Ceres, Ceres - GO, Brasil.

Data do recebimento: 10/02/2016

Data da aprovação: 25/03/2016
} 
pode-se verificar a eficácia da triagem clínica e a adequada triagem sorológica realizada com o candidato na doação no Hemoceres.

Palavras-chave: HIV. Inaptidão. Hemocentro. Doadores.

\section{ABSTRACT}

Introduction: Acquired Immune Deficiency Syndrome (AIDS) is a infection disease caused by the human immunodeficiency virus (HIV). The HIV propagation occurs by unprotected sex, contact with contaminated blood and vertical transmission during parturition or breastfeeding. Currently, there are few data in the literature about the prevalence of infection diseases by blood transfusion in brazilian population. Therefore, this study aims to analyze the seroprevalence of HIV 1/2 in candidates to blood donors in the region of Vale de São Patrício and Serra da Mesa served in Hemocentro Regional de Ceres-GO. Methodology: This is a restropective study data collection of quantitative aspect. Data were collected in Hemoceres in the period between January of 2010 and December of 2013. Results and discussion: Of the 8.838 donations made in Hemoceres, just 07 individuals (0.08\%) showed positive serology for HIV $1 / 2$. It is believed that the low prevalence of unsuitable donors detected in Hemoceres might be explained at first by the efficacy of clinical trial with the candidate in donation. It was found a bigger prevalence of unsuitable serological for HIV 1/2 in male gender individuals. For the marital status of unsuitable donors with positive serology it was found that $57.1 \%$ were married and $42.9 \%$ singles. About the age group, $57.1 \%$ of indivudals had more than 29 years old. Conclusion: In view of the data presented it can be verified the efficacy of clinical trial and the adequate serological trial held with the donor in the donation in Hemoceres.

Keywords: HIV. Disability. Hemocentro. Donors.

\section{INTRODUÇÃO}

A Síndrome da Imunodeficiência Adquirida/Acquired Immune Deficiency Syndrome (SIDA/AIDS) é uma doença infecciosa provocada pelo Vírus da Imunodeficiência Humana/Human Immunodeficiency Virus (VIH/HIV) pertencente à classe dos retrovírus. Os indivíduos contaminados pelo HIV são considerados HIV-positivos, no entanto, este só é considerado portador da AIDS quando se iniciam as manifestações clínicas da doença (SHARON, 2000; SOUZA; ALMEIDA, 2003).

Os primeiros casos da infecção ocorreram nos Estados Unidos, Haiti e África Central no fim da década de 1970 (BRASIL, [s/d]). No Brasil, desde a identificação do primeiro caso 
de AIDS na década de 1980 no estado de São Paulo até dezembro de 2013, cerca de 686.478 casos foram notificados no Sistema de Informação de Agravos de Notificação (SINAN), declarados no Sistema de Informação sobre Mortalidade (SIM) e registrados no Sistema de Controle de Exames Laboratoriais (SISCEL) e Sistema de Controle Logístico de Medicamentos (SICLOM). A região Centro-Oeste contribui com 39.691 das infecções notificadas e destas estima-se que cerca de 36\% dos casos tenham ocorrido no estado de Goiás (BRASIL, 2013).

A disseminação do HIV ocorre através da relação sexual sem proteção, contato com sangue contaminado no caso de hemofílicos ou indivíduos que se submeterem a transfusões sanguíneas e transmissão vertical durante o parto ou pelo aleitamento materno (QUEIROZ et al., 2012). A transfusão sanguínea até a década de 1980 era considerada uma simples transmissão de material biológico desprovida de grandes riscos ao receptor. Com a descoberta do vírus HIV, os bancos de sangue passaram a desempenhar um delicado e rigoroso controle do sangue doado através da realização de testes cada vez mais sensíveis (SEITZ; HEIDEN, 2010).

Com o intuito de eliminar todas as possibilidades de transmissão de infecções e melhorar a qualidade do hemocomponente a ser transfundido, a triagem em bancos de sangue é dividida em duas etapas. A primeira etapa, denominada triagem clínica, consiste na anamnese do candidato a doador, analisando sua história clínica e as correlacionando aos seus comportamentos. A segunda etapa é a triagem sorológica que, por sua vez, é a principal forma de evitar a transmissão de vários agentes etiológicos, dentre eles o HIV (PADILHA; WITT, 2011).

Os testes sorológicos para identificação de anticorpos anti-HIV passaram a fazer parte da rotina de triagem sorológica de bancos de sangue brasileiros a partir de 1985. Essa detecção pode ser feita por várias gerações de ensaio por imunoabsorbância ligado à enzima (Enzyme Linked Immunosorbent Assay - Elisa), ensaio imunoenzimático (Enzyme Immuno Assay - Eia), ensaio imunoenzimático com micropartículas (Microparticle Enzyme Immuno Assay - Meia) e ensaio imunoenzimático com quimioluminiscência. Como exames confirmatórios são realizados testes sorológicos que detectam a presença de anticorpos anti-HIV, tais como imunofluorescência indireta, imunoblot, Western Blot, além de testes virais que pesquisam RNA ou DNA viral, dentre eles o teste de amplificação de ácidos nucléicos (Polimerase Chain Reaction - PCR) e a amplificação sequencial de ácidos nucléicos (Nucleic Acid Sequence Based Amplification - Nasba) (BRASIL, 2004). Vale ressaltar que apesar de haver análises de biologia molecular altamente precisas como PCR e Nasba, os testes sorológicos ganharam a preferência 
devido à simplicidade de realização, elevada sensibilidade e especificidade (SHARON, 2000).

O Ministério da Saúde preconiza a realização de dois testes distintos que tenham antígenos e/ou princípios diferentes, além de pelo menos um deles ser capaz de identificar anticorpos anti-HIV-1 e anti-HIV-2. Posteriormente, a amostra deve ser submetida a teste confirmatório (PEREIRA; NASCIMENTO, 2004). Se em alguma etapa do processo um dos testes sorológicos der positivo, já se faz suficiente para descartar a bolsa de sangue (BRASIL, 2002).

Apesar da elevada sensibilidade e especificidade dos testes realizados atualmente, existe um período entre a contaminação com o agente etiológico e o surgimento de níveis detectáveis de anticorpos anti-HIV no soro do indivíduo denominado "janela imunológica" (ABBAS; LICHTMAN; POBER, 2000). Nesse período, os testes sorológicos do portador do vírus HIV apresentam-se negativos, porém há grandes possibilidades do vírus ser transmitido através de transfusão sanguínea (FERNANDES, 2001).

Diante da dificuldade de detectar o vírus durante a janela imunológica, novos testes estão sendo estudados a fim de propiciar uma maior segurança transfusional. A mais recente metodologia, que no Brasil está em processo de implantação, é a metodologia Nucleic AcidTest (NAT/Técnica de Detecção de Ácidos Nucléicos). No país esta metodologia já é realizada nos Hemocentros de São Paulo, Rio de Janeiro, Campinas, Bahia, Pernambuco e Brasília, com o objetivo de implantação em todos os serviços de hemoterapia nacionais futuramente (LIMA, 2011). A técnica de NAT, implantada na Legislação Brasileira pela Portaria $n^{\circ} 262$, de 2002 , detecta pequenos níveis de ácido ribonucléico (RNA) viral logo no início da infecção através da técnica de biologia molecular denominada Polimerase Chain Reaction (PCR - Reação em Cadeia da Polimerase) diminuindo consequentemente o período de janela imunológica de 1620 dias para 10-12 dias (DODD; NOTARI; STRAMER, 2002; KUCIRKA et al., 2011).

Atualmente, existem poucos dados na literatura científica em relação à prevalência de doenças transmissíveis por transfusões sanguíneas na população brasileira nas diferentes regiões do Brasil, especificamente em relação à inaptidão em candidatos à doação de sangue com sorologia positiva para HIV. Provavelmente isso se deve ao fato de que a realização de testes confirmatórios em amostras reativas pelos métodos de triagem sorológica não é obrigatória no país (BRASIL, 2004).

Dessa forma, o presente estudo teve por objetivo analisar a soroprevalência de HIV 1/2 entre os candidatos a doadores de sangue da região do Vale de São Patrício e Serra da Mesa 
(totalizando 31 municípios), que foram atendidos no Hemocentro Regional de Ceres - Goiás (Hemoceres), no período compreendido entre janeiro de 2010 a dezembro de 2013.

\section{METODOLOGIA}

O projeto para o desenvolvimento do presente estudo foi aprovado pelo Comitê de Ética em Pesquisa do Hospital Alberto Rassi - HGG sob o parecer n ${ }^{\circ} 423.515$.

\section{TIPO DE ESTUDO}

Trata-se de um estudo retrospectivo de levantamento de dados, de aspecto qualiquantitativo. Os dados foram coletados no Hemocentro Regional de Ceres- GO (Hemoceres), em Goiás, no período compreendido entre janeiro de 2010 a dezembro de 2013.

\section{CARACTERIZAÇÕES DO HEMOCENTRO REGIONAL DE CERES-GO}

O Hemocentro Regional de Ceres encontra-se localizado na região do Vale de São Patrício, no município de Ceres-GO, integrado à região Centro-Oeste. O Hemoceres é uma unidade em parceria com a Secretaria Municipal de Saúde, tendo como coordenador o Hemocentro de Goiás. Sua capacidade de atendimento é de cerca de 300 pacientes por mês, abrangendo toda a região do Vale de São Patrício e Serra da Mesa, compreendendo trinta e uma cidades, com exceção apenas do município de Minaçu, localizado na região Serra da Mesa. A prestação dos seus serviços baseia-se essencialmente na coleta de bolsas de sangue interna (coletado no Hemocentro Regional de Ceres) e externa (coletado em localidades com elevado fluxo de pessoas na cidade de Ceres e nas demais cidades integrantes). O Hemoceres é tido como referência pela coleta de sangue dos doadores aptos e distribuição de sangue, hemocomponentes e hemoderivados aos hospitais e clínicas públicas e privadas credenciadas de toda região do Vale de São Patrício e Serra da Mesa, sendo as doações de caráter voluntário. O laboratório do Hemoceres realiza triagem sorológica de alta sensibilidade - ELISA para HIV empregando os testes anti-HIV I e II e o NAT HIV.

\section{POPULAÇÃO DE ESTUDO}

Foram incluídos no estudo todos os candidatos a doação de sangue atendidos no Hemocentro Regional de Ceres-GO, que apresentaram soropositividade para o HIV 1/2 no período compreendido entre janeiro de 2010 e dezembro de 2013. Foram excluídos os 
indivíduos aptos a doadores e aqueles pacientes com sorologia positiva para outros agentes etiológicos.

\section{LEVANTAMENTO DE DADOS}

Foi realizado um estudo retrospectivo no período compreendido entre 2010 a 2013 no Hemocentro Regional de Ceres-GO (Hemoceres). Foram consultados os registros de todos os candidatos a doação de sangue, no entanto, apenas doadores com resultados de soropositividade para o HIV 1/2 foram incluídos no estudo. Além disso, dados como faixa etária, gênero e estado civil dos doadores também foram catalogados.

\section{VARIÁVEIS}

Foram analisadas as variáveis demográficas (gênero, faixa etária e estado civil), variável cronológica (período observado) e variável epidemiológica (prevalência) segundo os registros dos doadores. Foram levantadas como variáveis demográficas para a construção do perfil do candidato inapto a doador o gênero ao qual pertenciam, se masculino ou feminino. Quanto à faixa etária, foi designado o intervalo estabelecido pelo Hemoceres: 1) De 18 a 29 anos; 2) acima de 29 anos. Catalogou-se o estado civil relatado pelos indivíduos. A variável cronológica estudada foi o período de janeiro de 2010 a dezembro de 2013. A variável prevalência foi analisada frente a todos os casos soropositivos para HIV 1/2.

\section{ANÁLISE DE DADOS}

Os dados coletados foram organizados em planilha do programa Excel da Microsoft ${ }^{\circledR}$ para obtenção dos resultados em forma de Figuras e por análise estatística descritiva. Foram analisadas as variáveis demográficas, cronológicas e a prevalência para HIV 1/2 no Hemocentro Regional de Ceres, para posterior análise e interpretação dos resultados.

\section{RESULTADOS E DISCUSSÃO}

A busca por dados sobre a prevalência de sorologia positiva para HIV1/2 entre os doadores de sangue ainda são insuficientes para traçar um perfil consistente de inaptidão por HIV no Brasil. No entanto, historicamente, percebe-se uma baixa prevalência nos casos de contaminação por HIV por transfusão sanguínea notificados ao Ministério da Saúde na década de noventa (BRASIL, 2004).

O processo transfusional no Brasil e no mundo é uma medida terapêutica largamente 
utilizada, elevando a demanda por produtos hemoterápicos para grande parte da população que necessita do sangue e seus derivados para tratamento (ROHR; BOFF; LUNKES, 2012). Apesar do desenvolvimento de novas tecnologias de diagnóstico de doenças pelo sangue (triagem sorológica) e da adoção de medidas de segurança na triagem clínica com o intuito de eliminar os doadores com comportamento de risco, a transmissão do HIV ainda é um desafio nos serviços hemoterápicos devido ao risco de não o detectar durante a janela imunológica (BARRETO et al., 2005).

Acredita-se que a redução do número de testes positivos para o HIV em bancos de sangue, além das triagens clínicas e sorológicas bem conduzidas, pode ser explicada também pela criação dos Centros de Testagem e Aconselhamento (CTA), implantados no Brasil (SIQUEIRA, 2000; KUPEK, 2004).

Do total de 8.838 doações realizadas no Hemocentro Regional de Ceres-GO entre janeiro de 2010 a dezembro de 2013, apenas 07 indivíduos (0,08\%) apresentaram sorologia positiva para HIV 1/2 (Figura 1).

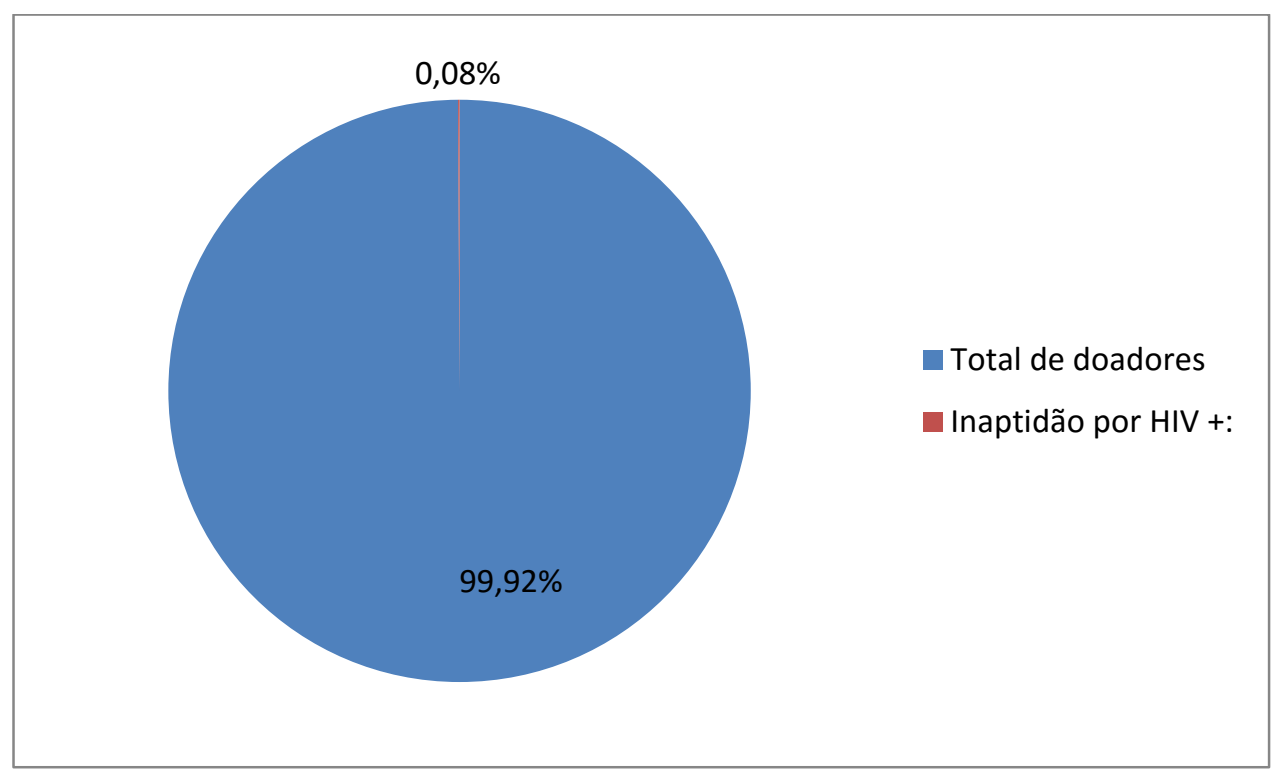

Figura 1: Soroprevalência de doadores inaptos para HIV durante triagem no Hemocentro Regional de Ceres-GO entre 2010 a 2013.

Para analisar os percentuais de doadores inaptos soropositivos para HIV utilizou-se como referência os dados disponíveis no Sistema Nacional de Informação da Produção Hemoterápica (Hemoprod). O Hemoprod é um boletim anual gerado pela ANVISA que disponibiliza os dados de produção concernentes aos serviços de hemoterapia no Brasil, entre eles a inaptidão sorológica para HIV. No entanto, estão disponíveis apenas três publicações 
para consulta, referentes aos anos de 2010, 2011 e 2012. Segundo o Hemoprod, o percentual de inaptidão sorológica para o HIV no Brasil no ano de 2010 foi de 0,36\%, em 2011 foi de 0,33\% e em 2012 foi de 0,37\% (BRASIL, 2012). Diante destes dados calculou-se uma média do percentual de inaptidão entre os anos de 2010, 2011 e 2012. A média encontrada foi de 0,35\% sendo, portanto, estabelecida como parâmetro para analisar a inaptidão de doadores neste estudo. Dessa forma podemos inferir que a prevalência de $0,08 \%$ referente aos doadores inaptos para doação com sorologia positiva para HIV no Hemoceres é considerada baixa.

A baixa prevalência de doadores inaptos com sorologia positiva para HIV 1/2 detectadas neste estudo (0,08\%) corrobora com os dados observados nos estudos de Ferreira (2007) em Ribeirão Preto - SP e Eustáquio et al. (2009) em Uberaba - MG, com 0,02\% e 0,07\% de doadores inaptos para doação com positividade para o HIV respectivamente. Acredita-se que as baixas prevalências de doadores inaptos $(0,08 \%)$ detectadas no Hemoceres possam ser explicadas a princípio, pela eficácia da triagem clínica realizada com o candidato na doação, eliminando dessa forma aqueles doadores com comportamento de risco (FERREIRA, 2007; EUSTÁQUIO et al., 2009).

Outra situação a ser considerada em relação à baixa prevalência é a presença dos CTAs, unidades de atenção à saúde que proporcionam à população acesso gratuito e anônimo para realização de testes sorológicos como HIV e hepatite. O acesso aos testes nos CTAs diminui de forma considerável a possibilidade destes indivíduos buscarem os hemocentros para realização destes diagnósticos, prática relativamente comum na população. Na microrregião atendida pelo Hemoceres, observa-se a presença de CTAs em Ceres e Uruaçu, além, é claro, do estado de Goiás contar com um total de 15 CTAs ativos atualmente. Diante disso, é importante ressaltar que em locais onde existem CTAs, normalmente são verificadas baixas prevalências de inaptidão sorológica nos serviços de hemoterapia. Essa situação ocorre em virtude da busca do CTA pela população para realização de testes como o HIV sem utilizarem o banco de sangue para este fim (BRASIL [s/d]; SIQUEIRA, 2000; KUPEK 2004; EUSTÁQUIO et al., 2009).

Conforme visualizado na Tabela 1, verificou-se uma maior prevalência de inaptidão sorológica para HIV1/2 em indivíduos do gênero masculino com 06 casos $(85,7 \%)$ confirmados. Apenas uma mulher (14,3\%) apresentou-se positiva para HIV na triagem sorológica. Outros estudos também descrevem o gênero masculino como predominante na inaptidão por HIV em bancos de sangue, Rohr, Boff e Lukes (2012) no Rio Grande Sul-RS, Vertchenko (2005) em Belo Horizonte-MG e Ribeiro (2004) em Pernambuco-PE, também 
verificaram essa situação (RIBEIRO, 2004; VERTCHENKO, 2005, ROHR; BOFF; LUNKES, 2012).

Segundo dados do Ministério da Saúde, é uma atitude comum os homens procurarem mais os serviços de hemoterapia para realizar doações do que as mulheres, fato este que explicaria o maior número de indivíduos do gênero masculino considerados clinicamente inaptos (BRASIL, 2004).

Outra causa a se considerar em relação à inaptidão entre homens deve-se principalmente à liberdade sexual vivenciada com a multiplicidade de parceiras (os) sexuais e a não adesão ao uso de preservativos, que os tornam mais suscetíveis às doenças adquiridas por via sexual (FRANCISCO; SPINDOLA, 2010). Acredita-se que o percentual de 14,3\% de inaptidão sorológica para HIV observado em mulheres neste estudo, seja em decorrência da doação de sangue não ser um hábito feminino. No entanto, apesar de o número de mulheres ainda ser menor, estudos apontam para a tendência epidemiológica de feminização da epidemia (PRAÇA; LATORRE, 2003).

Tabela 1: Perfil dos doadores inaptos à doação com sorologia positiva para HIV no Hemocentro Regional de Ceres-GO entre 2010 a 2013.

\begin{tabular}{lllll}
\hline & 2010 & 2011 & 2012 & 2013 \\
\hline Gênero & 3 & 2 & 1 & 0 \\
Masculino: & 0 & 0 & 0 & 1 \\
Feminino: & & & & \\
& 1 & 2 & 0 & 0 \\
Estado civil & 2 & 0 & 1 & 1 \\
Solteiro: & & & & \\
Casado: & & & & \\
& 2 & 1 & 0 & 0 \\
Faixa etária & 1 & 1 & 1 & 1 \\
18 até 29 anos: & & & & \\
Acima de 29 anos: & & & & \\
\hline
\end{tabular}

Quanto ao estado civil dos doadores inaptos com sorologia positiva para HIV no Hemoceres, verificou-se que $04(57,1 \%)$ indivíduos eram casados e $3(42,9 \%)$ solteiros. Estudos nos quais se verifica a situação conjugal dos doadores inaptos em bancos de sangue, os 
percentuais são significativamente maiores nos indivíduos solteiros conforme descrito por Eustáquio et al. (2009) e Pereira (2009) com 65,5\% e 59,1\% dos casos de inaptidão. Estes autores relatam que existe uma maior vulnerabilidade deste grupo no que diz respeito aos fatores de risco para o contágio do vírus quanto às práticas sexuais e ao uso de drogas ilícitas. Em relação ao grupo dos casados, Eustáquio et al. (2009) e Pereira (2009) descrevem percentuais de inaptidão para HIV de 34,5\% e 40,9\% respectivamente. Acredita-se que indivíduos casados apresentem percentuais menores de inaptidão por estarem menos expostos ao risco de transmissão da doença por manterem relações estáveis. É importante destacar que os dados de inaptidão para HIV descritos em indivíduos casados neste estudo $(57,1 \%)$, mostram uma inversão em relação aos valores descritos na literatura, onde os solteiros figuram com maiores percentuais. No entanto, já se observa registros de aumento dos casos de infecção entre os casados, como descrito por Santos, Marcellini e Ribeiro (2008), onde se ressalta a importância da conscientização e prevenção de homens e mulheres em relações estáveis (GUIMARÃES, 2000; BRASIL, 2007, SANTOS; MARCELLINI; RIBEIRO, 2008, EUSTÁQUIO et al., 2009, PEREIRA, 2009).

Em relação à faixa etária dos doadores inaptos com sorologia positiva para HIV, esta pesquisa verificou que $04(57,1 \%)$ dos indivíduos tinham acima de 29 anos. Contudo, os estudos realizados por Alcântara et al. (2006) e Eustáquio et al. (2009), mostram os maiores percentuais de inaptidão sorológica para HIV na faixa etária entre 18 a 29 anos. Uma vez que verificamos neste estudo um ligeiro aumento de inaptidão desta faixa etária (acima de 29 anos), podemos inferir que a doença está sendo adquirida mais tardiamente pela população. Dessa forma, devemos atentar ao fato de que não só a faixa etária jovem deve ser o foco nas campanhas de prevenção contra a AIDS (ALCÂNTARA et al., 2006; EUSTÁQUIO et al., 2009).

\section{CONCLUSÃO}

Este estudo permitiu verificar uma baixa prevalência $(0,08 \%)$ de inaptidão sorológica para HIV 1/2 no Hemocentro Regional de Ceres-GO. Observou-se que a maioria dos indivíduos inaptos à doação $(85,7 \%)$ pertencia ao gênero masculino, que o estado civil predominante dos inaptos foi o grupo dos indivíduos casados com $57,1 \%$ dos casos e que a faixa etária acima de 29 anos foi a que mais apresentou inaptidão sorológica. Diante dos dados obtidos pode-se verificar que a eficácia da triagem clínica e a adequada triagem sorológica realizada com o candidato na doação estão estreitamente relacionadas com o aumento na qualidade do sangue disponibilizado para transfusão na microrregião estudada. 


\section{REFERÊNCIAS BIBLIOGRÁFICAS}

ABBAS A.; LICHTMAN A.; POBER J. Cellular and Molecular Immunology. W. B. Saunders Company, 4. ed., 2000.

ALCÂNTARA, K.C.; FONSECA, A.F.; MODESTO, L.S.; SOUZA, E.M.; GONÇALVES, K.I. Soroprevalência de HIV - 1/2 entre doadores de sangue de Goiânia - Goiás. RBAC, vol. 38, n. 4, p.263-266, 2006.

BARRETO, C.C.; SABINO, E.C.; GONÇALEZ, T.T.; LAYCOCK, M.E.; PAPPALARDO, B.L.; SALlES, N.A, WRIGHT, D.J.; CHAMONE, D.F.; BUSCH, M.P. Prevalence, incidence, and residual risk of human immunodeficiency virus among community and replacement first-time blood donors in São Paulo, Brazil. vol. 45, n 11, p.1709-14, 2005.

BRASIL. ANVISA - Agência Nacional de Vigilância Sanitária. Boletim Anual de Produção Hemoterápica. Ano II nº 2, 2012.

BRASIL. Ministério da Saúde. Agência Nacional de Vigilância Sanitária. Manual técnico para investigação da transmissão de doenças pelo sangue. Brasília. Editora MS, 2004.

BRASIL. Ministério da Saúde. Agência Nacional de Vigilância Sanitária. Universidade Federal do Rio de Janeiro. Centro de Tecnologia e Ciências. Projeto Perfil do Doador de Sangue Brasileiro, 2004.

BRASIL. Ministério da Saúde. Boletim Epidemiológico: AIDS e DST. Ano IV $-\mathrm{n}^{\circ} 1-01^{\mathrm{a}} \mathrm{a}$ $26^{\mathrm{a}}$ semanas epidemiológica. Brasília, 2007

BRASIL. Ministério da Saúde. Boletim Epidemiológico: HIV/AIDS. Ano II $-\mathrm{n}^{\circ} 01$ até a semana epidemiológica $26^{\circ}$. Brasília, 2013.

BRASIL. Ministério da Saúde. Boletim Epidemiológico janeiro a junho de 2004

BRASIL. Ministério da Saúde. Centro de Testagem e Aconselhamento. Departamento de DST, Aids e Hepatites Virais. Portal sobre aids, doenças sexualmente transmissíveis e hepatites virais. [s/d]

BRASIL. Ministério da Saúde. História da Aids. Departamento de DST, Aids e Hepatites Virais. Portal sobre a AIDS, doenças sexualmente transmissíveis e hepatites virais. [s/d]. 
BRASIL. Ministério da Saúde. Portaria 1.376 de 19/11/1993. Aprovam normas técnicas para a coleta, processamento e transfusão de sangue, componentes e derivados. Rev. Bras. Hematol. Hemoter., vol. 24, n 1 , p.25-28, 2002.

BRASIL. Ministério da Saúde. Secretaria de Vigilância em Saúde. Programa Nacional de DST e Aids. Implicações Éticas do Diagnóstico e da Triagem Sorológica do HIV / Secretaria Vigilância em Saúde, Programa Nacional de DST e Aids. Brasília, 2004.

DODD R.Y.; NOTARI E.P.; STRAMER E.L. Current prevalence and incidence of infectious desease markers and estimated window period risk in the American Red Croos blood donor population. Transfusion. vol. 42, p. 975-979, 2002.

EUSTÁQUIO, J.M.J.; LIMA, G.M.; MARTINS, R.A.; SOUZA, H.M.; MARTINS, P.R.J.; Ocorrência de doações de sangue com sorologia positiva para o vírus HIV no Hemocentro Regional de Uberaba (MG) - fundação HEMOMINAS no período de 1995 a 2006. vol. 38, $\mathrm{n}^{\mathrm{o}} 2$, p. 73-81, 2009.

FERNANDES, M.F.A. Hemovigilância: análise das informações disponíveis para sua implementação, de acordo com a (re) investigação de casos de Aids associados à transfusão. Tese (Mestrado) Faculdade de Saúde Pública da Universidade de São Paulo, 2001.

FERREIRA, O. Estudo de doadores de sangue com sorologia reagente para hepatites $\mathbf{B}$ e C, HIV e Sífilis no Hemocentro de Ribeirão Preto. 2007. Dissertação (Mestrado) Universidade de São Paulo - Faculdade de Medicina de Ribeirão Preto/ Universidade de São Paulo.

FRANCISCO, M.T.R., SPINDOLA, T. AIDS na População Masculina e o Comportamento de Risco. Revista do Hospital Universitário Pedro Ernesto. vol. 9, p. 82-88, 2010.

KUCIRKA L.M.; SARATHY H.; GOVINDAN P.; WOLF J.H., ELLISON T.A.; HART L.J.; MONTGOMERY R.A.; ROS R.L. SEGEV D.L. Risk of window period HIV infection in high infectious risk donors: Systematic review and meta-analysis. American Journal of Transplantation. vol. 11, p. 1176-1187, 2011.

KUPEK, E. Transfusion risk for Hepatitis B, Hepatitis C and HIV in the State of Santa Catarina, Brazil, 1991-2001. Braz J Infect Dis, nº 8, p. 236-240, 2004. 
LIMA, D.S. Estudo Comparativo de Metodologias de Triagem para HIV e HCV em Doadores de Sangue. Academia de Ciência e Tecnologia. Brasília, 2011.

PADILHA, D.Z.; WITT, R.R.I. Competências da enfermeira para a triagem clínica de doadores de sangue. Rev. Bras. Enferm., Brasília, vol. 64, n², p.234-40, 2011.

PEREIRA, A.M.B.; NASCIMENTO, F. R. F. Prevalência de HIV entre doadores de sangue no banco de sangue do maranhão. DST - J. Bras. Doenças. Sex. Transm., vol. 16, nº 4, p.11$13,2004$.

PEREIRA, L.M.C.M. Perfil epidemiológico dos doadores de sangue da Fundação Hemopa em Belém- Pará, infectados pelo vírus da imunodeficiência humana. 2009. Dissertação (Mestrado em Biologia de Agentes Infecciosos e Parasitários) - Faculdade de Ciências Biológicas, Universidade Federal do Pará, Belém.

PRAÇA, N.S.; LATORRE, M.R.D.O. Saúde sexual e reprodutiva com enfoque na transmissão do HIV: práticas de puérperas atendidas em maternidades filantrópicas do município de São Paulo. Revista Brasileira Saúde Materno Infantil, Recife, v.3, n.1, p.61-74, jan./mar. 2003.

QUEIROZ, N.M.; SAMPAIO, D.A.; SANTOS, E.S.; BEZERRA, A.C. Modelo logístico na determinação de fatores associados à infecção HIV em doadores de sangue na Fundação HEMOPE. Rev. Bras. Hematol. Hemoter, vol. 34, no 3, p. 217-21, 2012.

RIBEIRO, P.B.C. Eficácia da triagem clínica de doadores de sangue da Fundação HEMOPE como método preventivo de doenças transmitidas por transfusão. 2004. Dissertação (Mestrado em saúde coletiva) - Universidade Federal de Pernambuco, Pernambuco.

ROHR, I.R.; BOFF, D.; LUNKES, D.S. Perfil dos candidatos inaptos para doação de sangue no serviço de hemoterapia do Hospital Santo Ângelo, RS, Brasil. Revista de Patologia Tropical. vol. 41, n. 1, p. 27-35, jan.-mar. 2012.

SANTOS, E.A.; MARCELLINI, P.S.; RIBEIRO, J.P. Avaliação epidemiológica das rejeições dos doadores de sangue no Hemolacen/SE no período de 2004 a 2006. RBAC, vol. 40, n. 4, p251-256, 2008.

SEITZ R.; HEIDEN M. Quality and Safety in Blood Supply in 2010. Transfusion Medicine and Hemotherapy, vol. 37, p. 112-117, 2010. 
SHARON, J. Imunologia básica. Rio de Janeiro. Guanabara Koogan, 2000.

SIQUEIRA, E.M.P. Perfil de risco e avaliação do teste rápido para o vírus da Imunodeficiência Humana em voluntários do Centro de Testagem e Aconselhamento na cidade de Goiânia-Goiás, 2000. Dissertação (Mestrado). Universidade Federal de Goiás, Instituto de Patologia Tropical e Saúde Pública.

SOUZA, M.V.N.; ALMEIDA, M.V. Drogas anti-VHI: passado, presente e perspectivas futuras. Revista Química Nova. São Paulo, v.26, n.3, p.366-372, maio/jun. 2003.

VERTCHENKO, S.B. Doação de sangue: aspectos sócio-econômicos, demográficos e culturais na região metropolitana de Belo Horizonte. 2005. Dissertação (Mestrado em saúde pública) - Universidade Federal de Minas Gerais, Belo Horizonte. 